\title{
MULHERES CAMPONESAS EM MOVIMENTOS: ANÁLISES DA ATUAÇÃO FEMININA NA VIA CAMPESINA, NA CAMINHADA PARA A SOBERANIA ALIMENTAR
}

\author{
Alzira Salete Menegat ${ }^{1}$ \\ Sandra Procópio Silva²
}

\begin{abstract}
Resumo: Este artigo tem por objetivo apresentar considerações sobre as condições e atuações das mulheres camponesas que integram a Via Campesina, considerando o contexto histórico cultural de produção da desigualdade entre homens e mulheres nas relações de trabalho, culminando com sua invisibilidade na produção de alimentos. Aliado a esse percurso, são analisadas as resistências das mulheres diante de processos opressores, descortinando-os e se colocando em lutas para transformação de relações sociais e de modelos de produção. Nesse sentido, a Via Campesina configura-se num coletivo que fortalece e fomenta a força social das mulheres, que visam a mudanças. Conclui-se que as Mulheres Camponesas, da Via Campesina, questionam as jornadas de trabalho opressoras, debatendo sobre processos que as fortaleça, como a soberania alimentar, os feminismos e a agroecologia.
\end{abstract}

Palavras-chave: Mulheres, Soberania Alimentar, Agroecologia, Via Campesina.

\section{INTRODUÇÃO}

Temas de estudos como Mulheres, Gênero, Patriarcado e Feminismos são fundamentais para compreendermos, nos dias atuais, como as mulheres, que representam metade da população mundial, se movimentam e criam resistências diante de estruturas sociais que historicamente insistiram e insistem em colocá-las em condição de inferioridade e desigualdade.

Os estudos direcionados aos citados temas representam ato de reflexão sobre a opressão social contra as mulheres, visto que, ao nascerem, são tratadas com inferioridade, pelo simples fato de serem mulheres. Nesse sentido, é importante desnaturalizar as relações de desigualdade e a classificação entre os seres humanos, compreendendo a hierarquização gestada pelo sistema

1 Doutora em Sociologia, professora nos cursos de graduação e de pós-graduação da Universidade Federal da Grande Dourados (UFGD).

2 Sandra Procópio da Silva é Mestre em Sociologia e Doutoranda em Geografia - UFGD. Professora da Licenciatura em Educação do Campo, na Faculdade Intercultural Indígena - UFGD. 
capitalista, que utiliza gênero, classe, racismo, padrão heterossexual como meios para exploração e subordinação. Por meio dessa hierarquização, cria teias que reproduzem o sistema de dominação e de exploração sobre as pessoas, em especial, as mulheres. Esse conjunto mostra-se configurado em múltiplas facetas, seja pagando-lhes menores salários no mercado de trabalho, seja restringindo espaços públicos e de poderes, expressos nos dados disponíveis. No caso brasileiro, esses dados são publicados nos sites das agências de pesquisas, como a Fundação Carlos Chagas, o Instituto de Pesquisa Econômica Aplicada/IPEA e o Instituto Brasileiro de Geografia e Estatística/IBGE, dentre outras.

No entanto, é preciso pautar que neste contexto de dominação emergem também resistências femininas, manifestadas ao longo da história da humanidade, as quais são construídas pelas mulheres em movimentos e tempos diversos, como: nos sindicatos, nas ruas, nas fábricas, nas universidades, nos coletivos de movimentos feministas e de movimentos sociais. Nessa perspectiva, questionam dominações e pautam demandas para a transformação social, que não se restringem apenas às mulheres, mas ao explicitar as diferenças e encaminhar demandas para sua superação, estão evidenciando o desejo de uma sociedade menos excludente e desigual.

No caso das mulheres inseridas no campo, elas são responsáveis por cerca de mais da metade da produção de alimentos no mundo, embora parte delas ainda não tenha consciência de sua importância e atuação. Nesse bojo, estão as Mulheres Camponesas, que atuam na Via Campesina, tema central do presente artigo.

A Via Campesina é uma organização de âmbito mundial, que reúne camponeses e camponesas articulados/as em redes (de demandas e de atuações), promovendo formações direcionadas à compreensão da sociedade num contexto global, especialmente, em relação ao modelo dominante de produção, implementado na maioria dos recantos do mundo. Aliado a esse conhecer e debater, os dilemas encaminham mobilizações, com ênfase nas avaliações do universo do campo, questionando os limites do modelo instituído. Esse modelo é hegemônico para a produção, pautando as possibilidades e a necessidade de emergência de novas formas de produzir e de se relacionar com a natureza, onde as especificidades de cada lugar sejam consideradas.

As mulheres defendem uma produção com base local, que congregue os saberes e as experiências de quem faz a produção acontecer, com produtos sem modificação genética e com atenção e interface com o ambiente onde são desenvolvidos. Recusam o pacote mercadológico, porque é tecnológico e de hegemonia, organizado em um único modelo, o qual controla tudo: a posse da terra, as relações de trabalho, o alimento e a vida. Além disso, pautam os saberes tradicionais para a produção de alimentos saudáveis, com olhar na qualidade de vida das pessoas envolvidas com sua produção. É com a lógica da soberania alimentar que tecem a rede de parcerias, composta por representantes de 81 países e 182 organizações sociais populares de camponesas e camponeses. No Brasil, a Via Campesina é composta por Movimento dos Atingidos por Barragens/MAB, Comissão Pastoral da Terra (CPT), Movimento dos Trabalhadores Rurais Sem Terra (MST), Conselho Indigenista Missionário (CIMI), Movimento dos Pequenos Agricultores (MPA), Movimento das Mulheres Camponesas (MMC).

As Mulheres organizadas na Via Campesina protagonizam ações concretas de combate ao capitalismo estrutural, questionam paradigmas e tradições culturais opressoras, que as coloca na condição de ajudantes, quando na prática ocupam a linha de frente da produção. São mulheres que descortinaram os elos do processo de dominação que as envolvia e, atualmente, estão propondo novas formas de luta e de enfrentamentos. Além disso, reivindicam direitos sociais e garantias de 
produzirem conforme suas próprias realidades e necessidades, rompendo amarras de modelos de produção engessados que controlam os alimentos e, também, inviabilizam e subjugam pessoas que produzem os alimentos básicos, dentre eles as mulheres, como veremos na sequência.

\section{MULHERES CAMPONESAS EM MÚLTIPLOS MOVIMENTOS}

A condição das mulheres camponesas possui determinadas semelhanças na sua forma de viver e de produzir alimentos, se consideradas as várias partes do mundo, como indicam os estudos de Deere e Lion (2002). Ampliando as reflexões das autoras, temos a pesquisa recentemente lançada pelo Instituto Interamericano de Cooperação para Agricultura (2019), o qual aponta que as mulheres que vivem nos campos do planeta produzem no mínimo $50 \%$ dos alimentos em seus países, e são $60 \%$ das pessoas que passam fome no mundo. Isso significa que o modelo hegemônico controla não apenas os meios para a produção, como as sementes, os insumos, a força de trabalho, as máquinas, a terra de plantio, mas também controla a distribuição do alimento produzido, fazendo com que cresça a desigualdade social, o que gera cada vez mais a fome em parte da população mundial, mesmo diante de um aparato tecnológico que tem possibilitado produzir em larga escala.

No que se refere ao reconhecimento da atuação das mulheres produtoras de alimentos e detentoras da posse das terras que cultivam, conforme dados da Organização das Nações Unidas para a Agricultura e Alimentação (FAO), nas últimas décadas, ocorreram poucas alterações no cenário, pois "no mundo há mais de 600 milhões de mulheres rurais, a maioria agricultoras, que representam mais da quarta parte da população mundial” (SENRA; LEÓN, 2009, p. 21), embora, contraditoriamente, "as mulheres, em nível mundial, somente dispõem de 1\% de terra". Para as pesquisas da Via Campesina:

As mulheres camponesas são as produtoras dos principais cultivos básicos em todo o mundo: arroz, trigo e milho, que proporcionam até $90 \%$ dos alimentos que consome a população empobrecida das zonas rurais. No sudeste da Ásia, as mulheres representam até $90 \%$ da mão de obra necessária ao cultivo de arroz. Na África subsaariana, as mulheres produzem até $80 \%$ dos alimentos básicos para o consumo familiar e venda, elas cultivam até 120 espécies vegetais diferentes nos espaços livres junto aos cultivos comerciais dos homens. As mulheres realizam de 25\% a 45\% das fainas agrícolas em Colômbia e Peru. Em algumas regiões andinas, as mulheres estabelecem e mantem os bancos de sementes do qual depende a produção de alimentos. Em Ruanda, as mulheres são as produtoras tradicionais de judia, conhecidas como a "carne" do campo, que aportam uma quarta parte das calorias e quase a metade das proteínas que ingere a população. As mulheres constituem 53\% da população trabalhadora agrícola no Egito (SENRA; LEÓN, 2009, p.22).

Ainda que a maioria das mulheres esteja produzindo alimentos em diversos lugares do planeta, necessariamente não significa que são elas que conduzem os processos de tomada de decisões sobre o que produzir e como produzir. Para Nalu Faria e Mirian Nobre (1997, p. 15), “[...] as mulheres executam $2 / 3$ do trabalho realizado pela humanidade, recebem $1 / 3$ dos salários e são proprietárias de 1\% dos bens imóveis. Dos quase 1,3 bilhão de miseráveis no mundo, $70 \%$ são mulheres". 
Menegat (2009) aponta que a invisibilidade da atuação das mulheres no campo brasileiro está associada ao tardio reconhecimento de sua condição como trabalhadoras, visto que no Brasil as mulheres conquistaram juridicamente esse direito com a Constituição de 1988, momento em que lhes foi assegurado o direito à aposentadoria aos 55 anos, bem como à licença maternidade.

Em relação à posse da terra em áreas de assentamentos rurais no contexto brasileiro, seguindo as reflexões de Menegat (2012), as mulheres passaram a compor o documento de titularidade dos lotes somente no ano de 2003, ou seja, 18 anos após a criação do I Plano Nacional de Reforma Agrária. O antigo Ministério do Desenvolvimento Rural (MDA) orientou para que o nome das mulheres fosse registrado primeiramente, e na sequência o nome do companheiro, num reconhecimento da presença e atuação delas nas unidades de produção, não só como produtoras, mas como mantenedoras das unidades, visto que as mulheres assentadas relutam em vender seus lotes, mesmo quando se encontram em situações de extrema dificuldade, como estarem em lotes com carência de água.

As pesquisas revelam que a agricultura no mundo inteiro, tecida pelas mãos das mulheres, tem acontecido no sentido de promover fundamentalmente o combate à fome, principalmente, nas áreas rurais. São geralmente as mulheres as primeiras que optam pela produção nos quintais gerando uma economia de autoconsumo, composto pelos alimentos que garantam o sustento imediato da família, seja pela horta e pelas frutas, seja pelos grãos ou pela criação de animais, bem como das ervas medicinais.

Além disso, as mulheres camponesas têm executado funções importantes, como, por exemplo, produtoras de alimentos, guardiãs dos recursos naturais, cuidadoras da nutrição das famílias, selecionadoras de importantes técnicas de armazenamento e processamento dos produtos, além de várias outras funções que passam pelo campo da produção, processamento e multiplicação de alimentos.

Entretanto, tem havido um movimento gestado pelas próprias mulheres do campo e da cidade para desvelar que este é um trabalho "invisibilizado" dentro do modo de produção capitalista ${ }^{3}$. No que se refere ao trabalho das mulheres em geral, não somente das camponesas, há um conjunto de atividades em que elas têm se mantido como organizadoras dentro do espaço familiar, cujas tarefas não são percebidas e, muitas vezes, nem mesmo por elas, como sendo um trabalho. As tarefas que proporcionam bem-estar ao núcleo familiar, como os cuidados com os idosos, as atenções especiais às crianças, a organização do espaço da família, a produção de alimentos para a reprodução dos membros de cada unidade, não são contabilizados.

O estudo de Menegat (2012) demonstra também a invisibilidade do trabalho doméstico como sendo critério estabelecido pelo referencial do sistema capitalista, que considera apenas como trabalho aquele que resulta em ganho financeiro. Nessa lógica, como no espaço da casa se consome o ganho oriundo de outros espaços, aplicado com aquisição de alimentos, vestuário, remédios, entre outros itens, camufla a ideia de rendimento, atribuindo o entendimento de que a casa é um lugar de valor nulo quanto à produção de riquezas, sentido que se estende também para quem nela atua, como ressalta a autora.

3 Farias (1983, p.85) apresenta o trabalho doméstico como uma das ocupações socialmente menos prestigiadas, "como um não-trabalho ('invisível'), de valor nulo, porque 'improdutivo' (lógica capitalista), não monetarizado (obrigação, virtude), e, portanto, desvalorizado". 
[...] sentido histórico, presente na explicação econômica, que retirava das mulheres a posição de trabalhadoras pelo fato de que a atividade doméstica estava voltada apenas à reprodução da família. Nela as mulheres não eram reconhecidas socialmente, pois trabalhavam em função "do e no lar", não produzindo riquezas que poderiam ser medidas em termos monetários. E, ainda mais, no espaço da casa eram consumidas as riquezas produzidas por outros membros da família, geralmente, homens, através do trabalho que investiam em outros espaços. A condição da mulher como apoio ao homem na medida em que ela deveria manter a organização da casa, no que se refere a sua reprodução, fez com que a invisibilidade econômica da casa projetasse também invisibilidade para as pessoas que encaminhavam a gestão da mesma, no caso, as mulheres, as que historicamente assumiram e/ou foram direcionadas ao espaço doméstico (MENEGAT, 2012, pp. 226-227).

Conforme Paulilo (2013, p. 295), a compatibilização entre os bens e os serviços que passam pelo mercado e os que não passam " [...] requer a descoberta de uma medida comum entre eles, o que é dificultado por três tipos de problemas: definição do que é trabalho; medição do tempo de trabalho; e atribuição de valor aos distintos tipos de trabalho".

Ora, se uma sociedade quer manter sua continuidade, os trabalhos de reprodução desta mesma sociedade não seriam de responsabilidade de todos/as os/as seus/suas envolvidos/as? Os trabalhos para garantir a reprodução e a sobrevivência da espécie humana não deveriam ser quantificados em horas de trabalho, revertidas para responsabilidade de todos/as? Se este trabalho - não quantificado - se mantém dentro das casas, na esmagadora maioria das vezes sendo feito pelas mulheres, quem ganha com isso? Por que este trabalho tende a ser considerado inferior aos demais trabalhos?

Segundo Menegat (2012), existe ainda no imaginário social o entendimento de que o trabalho doméstico segue pela classificação de "serviço" e não de um trabalho efetivo. Na dimensão de serviço, seu sentido assume a falsa lógica da leveza e por isso direcionado às mulheres, numa analogia ao sexo frágil, reforçando sua invisibilidade monetária, de poder e de força. Decorrente disso, a ideia da "ajuda", que no campo se manifesta fortemente como se as mulheres somente ajudassem (aos homens), mesmo quando elas lideram as decisões e atuações em relação ao plantar e ao comercializar.

Neste sentido, as lutas de várias mulheres em todos os cantos do mundo, na ótica de transgredir o que é considerado "normal", têm contribuído para questionar o modo de organização do modelo da sociedade onde vivemos, com base no perverso sistema capitalista. Esse questionamento ocorre especialmente no que tange às diferenças entre direitos para os homens, em detrimento dos direitos das mulheres, em todos os aspectos, seja nas enormes desigualdades econômicas, sociais, seja na reprodução dos modelos de opressão e violência, presente nos macro e micro espaços de poder. E, portanto, estas lutas têm ousado questionar os mecanismos que estão por trás da manutenção desta ordem social patriarcal.

\section{O TRABALHO INVISIBILIZADO DAS MULHERES}

O modelo patriarcal, que se impõe sobre a estrutura organizacional de toda a sociedade, leva-nos a "naturalizar" as relações sociais de modo desigual entre homens e mulheres, o que também 
está explícito nas relações do mundo do trabalho. O desafio é caracterizar o que é trabalho e o que não é trabalho. Outro desafio é medir o tempo de trabalho e os demais tempos, os quais são gastos com educação e lazer, por exemplo, e o valor que se dá a cada tipo de trabalho e quais os critérios são utilizados para imprimir um valor a cada função do posto de trabalho (PAULILO, 2013).

Diversos pesquisadores já tentaram fazer essa conta, embora continue sendo um desafio encontrar um ponto de equilíbrio entre levantar essas tarefas junto com os homens e, ao mesmo tempo, pautar a distribuição justa entre os tempos de cada um, afinal "[...] o trabalho em casa traz economia para a família, mas é invisível aos olhos da economia oficial, quando a mulher lava a roupa em casa, deixa de usar a lavanderia. Quando cozinha, não usa o restaurante. É um trabalho com valor econômico, sim" (CEPAT, 2005, p. 65). Esse trabalho foi calculado pelos pesquisadores do Jornal O Globo, em matéria de 11/09/2005, quando concluíram que custaria 12,76\% do PIB do país, ou R $\$ 225,4$ bilhões, em 2004, caso essa tarefa fosse paga as mulheres naquela ocasião.

As diferenças salariais entre homens e mulheres ainda persistem, de maneira geral. Segundo o IBGE, em pesquisa ${ }^{4}$ realizada em 2010, concluiu que a participação das mulheres no mercado de trabalho aumentou em $24 \%$ em dez anos. Porém, a mesma pesquisa conclui que as mulheres recebem $72,3 \%$ do valor que é pago aos homens em cargos iguais. E, além disso, as mulheres com filhos recebem quase $30 \%$ menos que aquelas sem filhos.

As desigualdades salariais expressam que, se de um lado as mulheres estão ocupando mais postos de trabalho, de outro lado, podemos considerar que são exploradas duplamente, por serem trabalhadoras e por serem mulheres. Se for negra, a situação é ainda pior. De acordo com estudos de 2013, do Instituto de Pesquisas Econômicas Aplicadas (IPEA), 69\% das mulheres negras chefes de família recebiam, em 2009, renda familiar de até um salário mínimo. O estudo conclui que, entre 1995 e 2009, as famílias chefiadas por mulheres negras mantiveram-se na posição de piores rendimentos, seguidas pelos homens negros, mulheres brancas e, por último, pelos homens brancos. A pesquisa ainda apresenta que, nas cidades, as famílias chefiadas por mulheres, entre 1995 e 2009 , passaram de $24,8 \%$ para 37,8\%. Já na população rural esse índice em 2009 era de $19 \%$, o que sinaliza o conservadorismo, a menor abertura do universo rural às mudanças e à igualdade entre os sexos.

Se na sociedade em geral ainda persistem grandes desigualdades entre homens e mulheres, ao olhar para a realidade do campo, esta situação torna-se ainda mais evidente. O trabalho desenvolvido pelas mulheres na unidade familiar camponesa, além de gratuito, é visto pela família apenas como "ajuda" revelando o quanto continua invisibilizado, como se não gerasse um valor econômico ou social. As tarefas de limpar, lavar, passar, alimentar, cozinhar, costurar, curar, gerar, criar e educar são costumeiramente realizadas pelas mulheres no meio rural. E mais, acrescentem-se as horas de trabalhos realizadas em torno da casa, no espaço chamado quintal, onde normalmente encontramos os pomares, as hortas, a criação dos pequenos animais, as pequenas experimentações, normalmente "cuidadas" pelas mulheres e crianças em idade escolar. Estas atividades garantem uma boa parte da alimentação da família, como as verduras, as frutas, os ovos, os derivados de leite, parte das carnes. Porém, esse trabalho nem sempre é visualizado como trabalho importante:

Verifica-se, como consequência da presença difusa desses estereótipos, a dupla desvalorização do trabalho da mulher: seu trabalho nas atividades relacionadas à

4 Carolina Montenegro, BBC Brasil, publicada em 13/05/2014. 
produção é considerado como sendo menor, ela apenas "ajuda", mesmo quando seu tempo de trabalho nas atividades relacionadas à produção não é menor que o realizado pelo homem. Por outro lado, as atividades relacionadas à reprodução não são valorizadas, o que conta é o que dá dinheiro (MENASCHE; TORRENS, 1996, p. 19).

Segundo a organização das Nações Unidas para a Agricultura e a Alimentação (FAO), no mundo, $70 \%$ das mulheres trabalhadoras rurais não têm remuneração, e, contraditoriamente, as mulheres não remuneradas têm carga de horas de trabalho maior que as remuneradas. $\mathrm{O}$ não recebimento está atrelado ao trabalho que é realizado dentro da unidade familiar, ou seja, não é contabilizado como trabalho. Portanto, não gera a renda monetária como uma renda mensal, de que falamos anteriormente. Existem mulheres, com parceiros ou não, que junto com seus filhos, dão conta de todos os afazeres domésticos, somados a todo o serviço da roça, organizando assim uma lógica que lhes permite sustentar materialmente e socialmente o seu núcleo familiar. Porém, isto não quer dizer que elas se reconheçam como trabalhadoras geradoras desta renda.

Em pesquisa, as próprias mulheres rurais declararam que trabalhavam apenas 21 horas por semana, quase metade do tempo declarado pelos homens, que foi de 39 horas semanais em média (BUTTO, 2011). Ao se reconhecerem trabalhadoras da metade do tempo que os homens, elas estão desconsiderando o tempo das horas gastas com o trabalho nas tarefas dentro do espaço da casa e nos quintais.

Nossas pesquisas ${ }^{5}$ demonstram que, em geral, as mulheres assentadas levantam-se em torno das $5 \mathrm{~h} 30$ e dormem às $21 \mathrm{~h}$, mantendo uma rotina de várias horas de trabalhos, sem descanso, com poucos intervalos. Então, embora elas estejam muitas horas de seu dia envolvidas em trabalhos, necessariamente não significa que o que fazem e produzem seja por elas considerado trabalho. Nesse sentido, "[...] a divisão sexual do trabalho está no cerne da argumentação do pensamento feminista sobre as diferenças entre o papel feminino e masculino” (MELO e CASTILHO, s/d).

Para a pesquisadora argentina Andrea D’Atri (2011, p. 149), esse modelo é ideal para o sistema capitalista, pois "[...] enquanto desenvolve as máquinas de lavar, a industrialização de alimentos etc., mantém a privatização das tarefas domésticas para que, desse modo, o capitalista seja isento de pagar grande parte do esforço com o qual garante a reprodução da força de trabalho".

Para Paulilo (2013, p. 293), “[...] nas últimas décadas, as tentativas de tornar visível a sobrecarga das mulheres tem posto ênfase nos estudos de uso do tempo por ambos os sexos". Em depoimento, numa visita que fez ao Mato Grosso do Sul, Rose Marie Muraro teceu o seguinte comentário sobre o modo de vida das trabalhadoras rurais da região:

Quem trabalha com as mulheres rurais sabe que elas não têm descanso, trabalham de manhã e de tarde na roça, fazem a comida, de noite cuidam das crianças doentes e ainda no sábado e no domingo lavam roupa enquanto os maridos jogam "pelada”. Quando

\footnotetext{
5 Citamos alguns projetos de pesquisas desenvolvidas de 2005 a 2015, com fomento do CNPq e FUNDECT: "Assentamentos rurais no sul de Mato Grosso do Sul: estudos econômicos e sociais das mudanças no meio rural”; "Sociedades e culturas nas fronteiras de Mato Grosso do Sul”, "Mulheres: relações de gênero e de trabalho nos assentamentos de reforma agrária Guaçu e Santa Rosa no município de Itaquiraí-MS", "Retratos da vida nos assentamentos Taquaral e Sul Bonito: as fotografias como instrumentos reveladores da (re)construção de novos lugares" e "Vida de mulheres em assentamentos de reforma agrária no município de Itaquiraí-MS”.
} 
eu falei isso para 1500 mulheres rurais no Mato Grosso do Sul, o auditório inteiro se levantou como se dissesse: “essa nos entendeu” (MURARO, 2005, p. 43).

Na perspectiva de uma possível análise da conjuntura, a partir da ótica feminista, mesmo com uma metodologia que procure contemplar a totalidade da realidade, é fundamental que, em nossas análises críticas, tenhamos o recorte de gênero. As reflexões realizadas pelas mulheres da Via Campesina, que reúne mulheres de vários movimentos sociais, deles participando há vários anos, como no caso as mulheres integrantes do MST e do MMC, vêm recolocando o tema dos feminismos como um debate necessário dentro das lutas de classes. A $5^{a}$ Assembleia Mundial de Mulheres da Via Campesina, ocorrida em 2017, no país Basco, teve como tema "Construímos movimento para mudar o mundo com feminismo e soberania alimentar".

A discussão que as mulheres camponesas tecem vem ao longo dos anos trazendo profundas reflexões, transpassadas pelo tema da agroecologia. Entretanto, compreendem que agroecologia não é um tema isolado em si mesmo, mas é enredado com os debates de classe, economia, cultura, política, sociedade, educação, saúde, e todos os que dizem respeito à vida humana, animal e ambiental. São as mulheres da Via Campesina que nas suas pautas defendem a necessidade que vai além da segurança alimentar e nutricional, trazendo à cena a soberania alimentar.

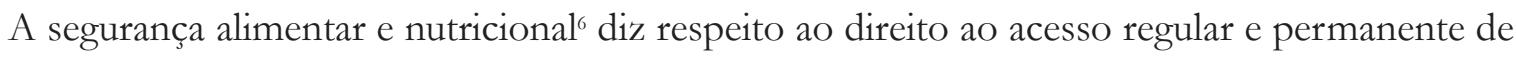
alimentos em qualidade e quantidade suficiente. A soberania alimentar, um conceito que parte dos movimentos sociais do campo da Via Campesina, vai trazer a importância da autodeterminação de cada povo sobre seus territórios e sobre seus processos completos de produção e reprodução, implicando a manutenção de seus costumes alimentares tradicionais, implementação de políticas públicas especiais para este objetivo, direito ao território, direito à água, direitos animais e da natureza.

\section{AS MULHERES E A AGROECOLOGIA NA CONSTRUÇÃO DA SOBERANIA ALIMENTAR}

A Via Campesina tem relacionado o tema da alimentação ao da soberania alimentar, trazendo para o debate as questões relacionadas ao direito à terra, à autonomia dos camponeses na escolha do que produzir. Também estão ligados ao conhecimento para produção, ao acesso a créditos agrícolas, à defesa das sementes crioulas, à recusa da transgenia, do agrotóxico, à defesa da produção com base na agroecologia. ${ }^{7}$ Enfim, a um conjunto de temas pelos quais passam o que denomina como soberania alimentar.

A Via Campesina elaborou, em 1996, durante o Encontro Mundial de Alimentação acontecido em Roma, a seguinte reflexão sobre soberania alimentar:

6 Lei Orgânica de Segurança Alimentar e Nutricional - LOSAN, Lei 11.346 de 15 de setembro de 2006, compreende que Segurança alimentar e nutricional é "realização do direito de todos ao acesso regular e permanente a alimentos de qualidade, em quantidade suficiente, sem comprometer o acesso a outras necessidades essenciais, tendo como base práticas alimentares promotoras de saúde que respeitem a diversidade cultural, e que sejam ambiental, cultural, econômica e socialmente sustentáveis. 7 Há várias sistematizações organizadas pelos movimentos sociais de mulheres do campo. Entretanto, optamos aqui por um conceito construído coletivamente a partir de Barinas-Venezuela com representantes de 46 organizações de 16 países, no I Encontro de Formação de Formadores (as) em Agroecologia, em 10 a 20 de agosto de 2009. 
É o direito de cada povo definir suas próprias políticas agropecuárias em matéria de alimentação, de proteger e regulamentar a produção agropecuária nacional e o mercado doméstico a fim de alcançar metas de desenvolvimento sustentável, de decidir em que medida quer ser autossuficientes, de impedir que seus mercados se vejam inundados por produtos excedentes de outros países que os colocam no mercado internacional mediante a prática de "dumping” (VIA CAMPESINA, 1996)

As mulheres camponesas articuladas na Via Campesina resgatam o conceito de agroecologia, construído coletivamente e por onde passa sua defesa. Por esta linha de pensamento, a agroecologia transcende o conhecimento técnico e científico e perpassa o modo de relações sociais e práticas individuais e coletivas. Essas estão pautadas na luta por um conjunto de transformações profundas das relações econômicas, sociais, políticas, culturais (leiam-se também patriarcais). Assim, para as mulheres da Via Campesina, a agroecologia pode ser pensada como:

Parte de nossa ancestralidade e de nossa maneira dinâmica e racional de ser parte da natureza respeitando a biodiversidade, seus ciclos e seu equilíbrio. É uma de nossas formas de luta contra o avanço do capitalismo e toda forma de dominação, por isso, uma construção política, popular, social, cultural, ancestral, cientifica, econômica, estratégica e de classe (Via Campesina, 2009).

As mulheres em suas ações, à medida que fortalecem o debate do modelo de agroecologia com base nas tradições camponesas, fazendo a defesa de uma produção que considere os conhecimentos e as experiências tradicionais, atentando para o meio ambiente, na relação com a natureza, colocam em questão o modelo capitalista, que é depredatório porque objetiva produzir em larga escala considerando apenas o acúmulo de capital. Com isso, ao mesmo tempo, promovem a denúncia de que o capitalismo transforma tudo em mercadoria, inclusive a água, a terra, o ar, os alimentos. Ao defenderem relações de produção com equilíbrio com a natureza, contrapõem-se ao tradicional modelo de latifúndio e ao "moderno" modelo do agronegócio, ambos combinados com a exploração de trabalhadores, o êxodo rural, o analfabetismo, a pobreza.

No que se refere ao protagonismo das mulheres, vale destacarmos que, nos últimos anos, as mulheres, organizadas através da Via Campesina, protagonizaram ações mais radicais, posicionando-se em lutas contra-hegemônicas. De modo especial, as ações realizadas anualmente no dia 8 de março em vários Estados do Brasil e do Mundo têm sido uma mostra de seu potencial denunciador. Essas ações, no Brasil, são parte da estratégica "Jornada Nacional de Lutas das Mulheres Sem Terra", realizada anualmente, que parte de uma temática de interesse coletivo, promovendo estudos da realidade, organizando estratégias e participação dos vários movimentos de mulheres camponesas em ações concretas.

A Jornada Nacional de 2013 pautou a denúncia contra o capital estrangeiro na agricultura, bem como contra o agronegócio e pela soberania alimentar. Em 2014, o lema foi "Mulheres Sem Terra na luta contra o capital e pela Reforma Agrária".

No caso do Mato Grosso do Sul, em 2013, cerca de 600 mulheres mobilizadas pelo Movimento dos Trabalhadores Sem Terra (MST) e Via Campesina ocuparam a rodovia em Nova Alvorada do Sul, cidade que detém histórico expressivo de número de usinas de processamento da cana-de-açúcar, protestando na BR 163. Na ocasião, fizeram uma marcha e pautaram a contaminação do 
Aquífero Guarani pelos agrotóxicos e os monocultivos da cana de açúcar.

Nos anos de 2013 e 2014, as mulheres da Via Campesina e do MST em Mato Grosso do Sul uniram-se às mulheres indígenas aglutinando lutas com bases comuns, como as denúncias dos impactos das usinas sobre a vida e o meio ambiente. No ano 2016, a campanha foi pelos direitos "Nenhum direito a menos". Em 2017, o recado foi "Estamos todas despertas! Contra o capital, contra o agronegócio!". Em 2018, o lema "Quem não se movimenta, não sente as correntes que a prendem!". E neste ano de 2019, "Pela Vida das Mulheres, somos todas Marielle!".

As ações realizadas nos locais, campo e cidade, tendem a se constituírem em momentos fortes de aglutinação e ampliação da consciência política em relação às lutas mais amplas, encabeçadas pelos diferentes movimentos de mulheres camponesas e urbanas do planeta, sintonizadas com as necessidades de mudança no conjunto da sociedade global. Para as mulheres da Via Campesina, é a agroecologia uma das suas bandeiras de luta nos últimos períodos, assim como as lutas contra o patriarcado,

\footnotetext{
Necessária para que os povos garantam a soberania alimentar e energética para a emancipação humana, também, a agroecologia é vital para o avanço da luta dos povos para a construção de uma sociedade onde não haja propriedade privada dos meios de produção e dos bens naturais, sem nenhum tipo de opressão e exploração, cujo fim não é a acumulação (Via Campesina, 2009).
}

A Via Campesina " [...] criou e tem insistido na ideia de soberania alimentar. Por trás deste conceito está um conflito de modelos de agricultura (e de mundo) que alguns autores têm identificado como de contra hegemonia" (VIEIRA, 2012, p. 205). As mulheres se posicionam na defesa de seus conceitos, como campesinato e agroecologia, e por trás deles, o sentido de mundo e a defesa de seu mundo.

\footnotetext{
Ao resgatar o termo camponês como articulador da diversidade de categorias existentes no meio rural, a Via Campesina posiciona-se contra os efeitos da globalização e das políticas neoliberais no campo, em especial no que se refere ao empobrecimento, à destruição das culturas locais, do meio ambiente e à provocação de desenraizamento dos trabalhadores do campo e migrações (MEDEIROS, 2003, p. 66).
}

Temos visto em nossas pesquisas de campo que grande parte das mulheres assentadas praticam técnicas de agroecologia mesmo sem terem acesso ao conhecimento mais elaborado do que seriam as bases epistemológicas deste modelo. A prática que vem sendo cultivada pelas mulheres diz respeito a conhecimentos geracionais, os quais foram sendo passados de mães e avós para as gerações descendentes, no que diz respeito à produção, técnicas de armazenamento, multiplicação de espécies, processamento de alimentos, conhecimentos dos ciclos da natureza, entre outros. Atualmente, esses conhecimentos estão sendo fortalecidos pelos debates encaminhados pelos movimentos sociais, numa defesa da produção com base camponesa, como estímulos para novas práticas que levem em consideração os saberes tradicionais, num respeito aos conhecimentos, à vida e ao meio ambiente.

As feiras com produtos agroecológicos e de produção orgânica, organizadas no contexto das cidades, também têm crescido na última década e vêm conquistando consumidores atentos à 
qualidade dos produtos e preocupados com o ambiente. Assim, as feiras configuram-se como espaços que podem ampliar o debate em torno da necessidade de se fortalecer novos procedimentos em relação à produção e à forma como se produz.

Com essa mesma lógica, vem acontecendo as feiras de sementes nativas e crioulas no campo, onde estão especialmente mulheres e são lugares onde é possível a troca de sementes sem modificação genética, bem como a troca de experiências agroecológicas. Nesse contexto, também são fortalecidas as sociabilidades das pessoas defensoras de um novo modelo de produção, em sua maioria de mulheres.

Podemos dizer que as trocas de variedades em geral cumprem esta função, quando, por exemplo, favorecem que determinada variedade de planta fique protegida dentro de uma comunidade por várias pessoas, servindo como uma espécie de "poupança de mudas". Desse modo, cada vez que a pessoa que doou perde sua muda, ela saberá onde reencontrar. Este processo também acontece com as mudas de frutas, de flores silvestres, de árvores nativas, de flores ornamentais, de grande quantidade de alimentos. Assim, gera uma grande variedade de biodiversidade que ainda pode ser visualizada dentro das comunidades camponesas.

\section{CONSIDERAÇÕES FINAIS}

Os movimentos sociais articulados na Via Campesina têm cada vez mais pautado a bandeira da soberania alimentar como um conceito que tenta aglutinar em si um conjunto de ações, as quais estão se tornando novos paradigmas na luta de mulheres e homens dos movimentos sociais do campo, na América Latina e no Brasil. Essa articulação tem reflexos em todos os assentamentos vinculando às lutas das mulheres camponesas, articuladas em redes amplas pelo direito às condições dignas de vida. Nesse sentido, o tema da soberania alimentar refere-se a um novo paradigma no debate sobre o tema da alimentação, com forte participação das mulheres camponesas.

Os desafios são muitos, contudo, as práticas agroecológicas gestadas em grupos, bem como em unidades familiares, associações, grupos de indígenas, quilombolas, camponeses e, ainda, de mulheres, de jovens, têm cumprido a importante função de cuidar para que a vida humana seja preservada, mostrando que existe outra lógica para além do acúmulo de capital.

O coletivo de mulheres, como ocorre na Via Campesina, possibilita ampliação de conhecimentos e fortalece a luta em defesa da soberania alimentar. A mensagem é que uma mulher camponesa sozinha não pratica todas as técnicas, até porque cada mulher sabe um pouco de cada coisa e aperfeiçoou mais determinado conhecimento em função de suas práticas agrícolas. Porém, nas suas práticas cotidianas, algumas delas cultivam técnicas que nem mesmo imaginam fazerem parte da agroecologia, estudadas como ciência e valorizadas como um dos aspectos que atualmente estão sendo reelaborados como conhecimento tradicional, que há muito se perdeu em função do atual modelo de produção agrícola, que priorizou as monoculturas e o pacote tecnológico.

Tais encaminhamentos se firmam nas mulheres como liderança, seja nos questionamentos sobre o modo de produzir alimentos, seja na luta para transformar a produção e também eliminar a dominação. Visa-se, assim, construir novas relações sociais em que elas participem e construam o modelo de produção, atendendo ao que lhes interessa e não ao que economicamente se propaga. Essa é a lógica da soberania alimentar, que tem na Via Campesina o espaço para recarregar energias, com troca de experiências, com a apresentação de questionamentos e enfrentamentos sociais visando à contestação de modelos dominantes e dominadores. 
As mulheres da Via Campesina defendem a produção combinada com conhecimentos tradicionais e científicos, mediados pelas experiências de todas as pessoas, atentando para as necessidades de cada lugar, em que é possível a gestão do território para plantar alimentos para o corpo e para os sentidos.

Enfim, essa reflexão é um tributo a Valdirene de Oliveira, uma mulher valente, de fala e de ação forte e decidida, atuante que foi nos encaminhamentos do MST, na Via Campesina, no assentamento onde produzia alimentos em Mato Grosso do Sul, e que certa vez nos disse o seguinte: quando uma camponesa planta flores é porque ela já organizou seu lote e conseguiu plantar e colher alimentos. Desejamos que em nossas práticas, possamos trilhar uma caminhada para o bem viver e nela colher alimentos diversos: ideias, experiências, flores, frutos, solidariedades e abraços.

\section{REFERÊNCIAS}

BUT'TO, Andrea. Política para as mulheres rurais: autonomia e cidadania. In: BUTTO, Andrea; DANTAS, Isolda (org.). Autonomia e cidadania: políticas de organização produtiva para as mulheres no meio rural. Brasília: Ministério do Desenvolvimento Agrário, 2011.

CARRASCO, Cristina. In: A produção do viver. NOBRE, Miriam; FARIAS, Nalu (org.). Sempre Viva Organização Feminista (SOF). São Paulo: 2003.

DEERE, Carmen Diana; LEON, Magdalena. O Empoderamento da Mulher: direito à terra e direitos de propriedade na América Latina. Tradução Letícia Vasconcelos Abreu, Paulo Azambuja Rossato Antinolf, Sônia Terezinha Gehring. Porto Alegre, RS: Editora UFRGS, 2002.

D’ATRI, Andrea. Feminismo e marxismo: 40 anos de controvérsias. Revista Lutas Sociais, São Paulo, n. 27, p. 142-156, 2011.

FARIA, Nalu; NOBRE, Miriam. Gênero e Desigualdade. São Paulo: SOF, 1997.

FARIAS, Marisa de Fátima Lomba de. Mulheres no Movimento dos Trabalhadores Rurais Sem Terra (MST). In: TEDESCHI, Losandro Antonio (org). Leituras de gênero e interculturalidade. Dourados: Editora UFGD, 2013.

MEDEIROS, Leonilde Servolo. Reforma Agrária no Brasil - história e atualidade da luta pela terra. São Paulo: Fundação Perseu Abramo, 2003.

MELO, H.P.; CASTILHO, M. Trabalho reprodutivo no Brasil: quem faz? Revista, v.13, n1. http://www.scielo.br/pdf/rec/v13n1/06.pdf

MENASCHE, Renata; TORRENS, João Carlos Sampaio. Gênero e Agricultura Familiar. DESER/ CEMTR/PR. Curitiba: Deser, 1996.

MENEGAT, Alzira Salete. Mulheres assentadas abrem novas portas. Quais as portas? In: MENEGAT, Alzira Salete, FARIAS, Marisa de Fátima Lomba, TEDESCHI, Losandro. Educação, relações de gênero, movimentos sociais: um diálogo. Dourados: UFGD, 2009. (pp.207-233) 
MENEGAT, Alzira Salete. Mulheres assentadas e acadêmicas construindo novos pertencimentos sociais. In: PINHEIRO, Alexandra Santos, et al. Saberes da Terra: teorias e vivencias. Dourados: UFGD, 2012 (pp.223-247)

MURARO, Rose Marie. Aspectos históricos e políticos da violência contra as mulheres. Revista CEPAT Informa, n. 126, Especial, Set. / 2005.

SENRA, Lídia; LEÓN, Irene. Las mujeres Gestoras de la Soberanía Alimentaria. In: Las mujeres alimentan al mundo. Soberania alimentaria em defensa de la vida y del planeta. Barcelona: Entrepueblos, 2009.

PAULILO, Maria Ignez S. FAO, Fome e Mulheres Rurais. DADOS - Revista de Ciências Sociais, Rio de Janeiro, vol. 56, n. 2, 2013, p. 285-310.

VIA CAMPESINA, Declaración sobre la Soberanía Alimentaria de los Pueblos - 2009: http://www. viacampesina.org. Acesso em 25 de junho de 2013.

VIEIRA, Flávia Braga. Articulações Internacionais “desde abaixo” em tempos de globalização. In: GONH, Maria da Glória; BRINGEL, Breno (orgs.). Movimentos Sociais na era global. Petrópolis: Vozes, 2012. 